\title{
4 \\ AUTOMATIC COGNITIVE PROCESSES AND NONVERBAL COMMUNICATION
}

\section{- Jessica L. Lakin}

\section{Drew University}

$\mathrm{N}$ onverbal behavior is arguably one of the most powerful methods of communication; it conveys important information about a person's likes and dislikes, emotions, personal characteristics, and relationships (e.g., intimacy, dominance, trust, similarity). Whereas no one would be surprised that verbal communication of this type of information has a cognitive basis, messages conveyed and received nonverbally also have their basis in cognitive processes, although not always in conscious, controlled ones. Thus, understanding nonverbal communication relies, to some extent, on appreciating its cognitive foundation. This cognition refers to the mental activities and processes in which humans (and other animals) engage. Cognitive activities include, but are not limited to, learning, receiving, storing, processing, judging, and using information (Neisser, 1967).

The cognitive processes associated with nonverbal communication can occur with awareness, but they are also likely to, and in fact often do, occur without conscious awareness (for a review, see Hassin, Uleman, \& Bargh, 2005). The purpose of this chapter is to review the 
automatic cognitive bases of nonverbal behaviors. To accomplish this objective, I first discuss what it means for a cognitive process to be (relatively) automatic or (relatively) controlled. This is followed by specific examples of nonverbal communication that appear to be relatively automatic. I then conclude with a discussion of important issues and future directions, including methodological considerations, the role of controlled processes, and the importance of cognitive resources.

\section{- Automatic and Controlled Processes}

In 1975, Posner and Snyder considered a basic question of human existence: How much control do people have over their thoughts, behaviors, and decisions? Since they posed their question, researchers have demonstrated that much of what we do cognitively happens without intention, awareness, or conscious control (Hassin et al., 2005). Although the history of automaticity and automatic processes has been reviewed in extensive detail elsewhere (Bargh, 1994, 1996, 1997; Bargh \& Chartrand, 1999), a basic discussion of what it means for a process to be more controlled or more automatic seems necessary before turning attention to specific examples of nonverbal communication and their relationship to automatic cognitive processes.

Controlled processes are characterized by awareness, intentionality, controllability, and cognitive effort (Bargh, 1994, 1996; Posner \& Snyder, 1975; Shiffrin \& Schneider, 1977). Aspects of awareness include recognizing the cognitive process or stimulus consciously, but they also involve an acknowledged recognition of the influence that the process or stimulus is having. Intentionality refers to the necessity of an act of will to start the process, whereas controllability refers to the fact that an act of will can stop the process once it has been started (i.e., it does not run to conclusion autonomously). Finally, and despite the limited amount of cognitive resources that people have and the already high demands on these resources, controlled processes require a share of these limited attentional resources (i.e., they require cognitive effort).

Automatic processes are more difficult to define. Because the four characteristics associated with controlled processes do not occur in an all-or-none fashion, it is not correct to assume that automatic processes are, by default, characterized by unawareness, unintentionality, and uncontrollability and require no cognitive effort. Although a process that has these four characteristics would certainly be considered automatic, processes that are characterized by one, two, or even three of these features have also been referred to historically as automatic (Bargh, 1994, 1996, 1997). It is also possible for various combinations of these four basic characteristics to occur. For example, experienced drivers intend to get in a car and go somewhere, even if when they arrive, they have no conscious awareness of anything that occurred during the trip. This example demonstrates that there are several types of automatic processes, resulting in a continuum of automaticity (ranging from completely automatic to completely controlled) rather than a simple dichotomy (Bargh, 1996, 1997; Bargh \& Chartrand, 1999).

Specifically, preconscious automaticity represents the completely automatic end of the continuum, because it corresponds to the initial unconscious processing of incoming environmental information. This analysis occurs without intention, control, or awareness, and it is largely effortless. Goaldirected automaticity, however, represents a point somewhere in the middle of the 
continuum, because it corresponds to intentional, controllable processes that become automatic and effortless over time. Both preconscious and goal-dependent automatic effects are autonomous: Once the processes are started, they operate by themselves without awareness and conscious guidance. Regardless of whether an automatic effect is preconscious or goal dependent, it is possible for it to become controlled if a person becomes aware of the process. Conscious processes that are effortful, intentional, and controllable represent the completely controlled end of the continuum (Bargh, 1996, 1997; Bargh \& Chartrand, 1999).

Recent research from the cognitive, social, comparative, and neuroscience literatures has demonstrated a strong associative link between perceptions from the environment and the brain regions associated with producing the observed behavior (i.e., a perception-behavior link; Bargh \& Chartrand, 1999; Bargh, Chen, \& Burrows, 1996; see Dijksterhuis \& Bargh, 2001, for a review). This memory-based link results in relevant, associated behaviors becoming activated automatically on perception of a stimulus. Although the perceptionbehavior link posits an unmediated relationship between perception and behavior, the existence of this link is dependent on the fact that ideas are represented mentally (i.e., cognitively). Therefore, in a sense, some type of minimal cognitive mediation is involved (Dijksterhuis \& Bargh, 2001).

\section{$\checkmark$ Automatic Effects in Social Evaluation and Behavior}

There is an impressive abundance of automatic preconscious and goal-dependent effects relevant to nonverbal communication demonstrated in the social cognition literature. Some of these effects have been argued explicitly to be a result of the perception-behavior link. As with the historical conception of automaticity, there are quite a few reviews of these effects (Bargh \& Chartrand, 1999; Wheeler \& Petty, 2001), but I begin with a brief review here to place automatic nonverbal communication effects in context.

\section{IMPRESSIONS}

Impressions of other people can be affected automatically by activation of relevant knowledge structures. Srull and Wyer (1979) demonstrated this when they made traits related to "hostility" or "kindness" accessible to participants and then asked them, in an ostensibly unrelated task, to form an impression of a person whose behaviors were ambiguously hostile or ambiguously kind. Their results indicated that participants were likely to interpret the ambiguous behaviors in a manner consistent with the traits that had been made accessible previously. Higgins, Rholes, and Jones (1977) demonstrated a similar effect with the activation of either positive (e.g., adventurous) or negative (e.g., reckless) traits relevant to a person's behaviors (e.g., crossing the Atlantic in a sailboat). Participants evaluated the target person more positively when the activated traits had positive connotations than when they had negative connotations. People's impressions were affected by accessible constructs without intention or awareness.

From these two classic demonstrations, an entire literature on spontaneous trait inferences grew (Uleman, 1999; Uleman, Newman, \& Moskowitz, 1996; Winter \& Uleman, 1984). It also became clear that impressions are based on traits that are chronically accessible (i.e., personally important; Higgins, 1996) as well as traits 
that are temporarily accessible (i.e., primed; as in the work by Higgins et al., 1977; Srull \& Wyer, 1979) and that salient physical cues (e.g., sex, race) can automatically activate stereotypes associated with particular groups of people (Brewer, 1988; Devine, 1989; Fiske \& Neuberg, 1990). Together, this work demonstrates that people make inferences about the behaviors of others, without intention, control, effort, or awareness of having done so. Many of these behaviors are nonverbal cues.

\section{BEHAVIOR}

Behavior is also affected automatically by external stimuli. In the first demonstration of this idea, Bargh et al. (1996) showed that activating the trait "rude" caused people to interrupt an experimenter who was ostensibly helping a confederate more quickly than did participants who had the trait "polite" activated. This finding has been replicated in a number of behavioral domains: Activating "politicians" causes long-windedness (Dijksterhuis \& van Knippenberg, 2000), and activating "supermodels" causes poor performance on a trivia test, whereas activating "professors" causes better performance (Dijksterhuis \& van Knippenberg, 1998).

Likewise, activating traits associated with conformity causes people to agree more with a group of confederates (Epley \& Gilovich, 1999); activating helpfulness traits causes people to be more helpful (Macrae \& Johnston, 1998); activating aggressionrelated ideas causes people to give longer "shocks" to another participant (Carver, Ganellen, Froming, \& Chambers, 1983); activating the elderly stereotype causes people to walk more slowly (Bargh et al., 1996), increases slowness on a lexical decision task (Dijksterhuis, Spears, \& Lepinasse, 2001), and promotes poor memory (Dijksterhuis, Aarts, Bargh, \& van Knippenberg, 2000; Levy, 1996); and activating stereotypes for African Americans causes hostility (Bargh et al., 1996) and decreased intellectual performance (Steele \& Aronson, 1995; Wheeler, Jarvis, \& Petty, 2000). As evidenced by the social inappropriateness of many of these behavioral effects, participants are not aware that they are occurring and are not being affected intentionally, nor do they seem to be able to control the effects that the activation of the various constructs is having.

\section{ATTITUDES}

Just as impressions are formed automatically when traits are accessible, either chronically or temporarily, evaluations of stimuli are activated automatically when the stimuli are presented. This automatic evaluation work can be traced back to Zajonc (1980), who argued that the evaluation of a stimulus is connected closely to the representation of the stimulus itself. That is, when the stimulus is presented, a positive or negative evaluation of that stimulus becomes activated without awareness, effort, or intention. In support of this idea, research has demonstrated that attitudes are activated automatically when a stimulus is presented (Bargh, Chaiken, Govender, \& Pratto, 1992; Fazio, Sanbonmatsu, Powell, \& Kardes, 1986).

Using a procedure similar to the activation of impressions and behaviors, Kawakami, Dovidio, and Dijksterhuis (2003) have even found that when a stereotype is made accessible, people report attitudes consistent with the stereotypical attitudes of that group. For example, when the category of "elderly" is accessible, people report more conservative attitudes, and when the category "skinhead" is accessible, people report more prejudiced attitudes. These effects occur even when the categories were made accessible to participants with a subliminal priming procedure, again suggesting that this effect occurs without conscious awareness. 


\section{GOALS}

In addition to impressions, behaviors, and attitudes, it has been proposed that goals can become active automatically. Because goal-related information and behaviors are represented mentally, if a goal is pursued frequently and consistently in a particular context or with a particular person, the context or person alone will eventually be able to activate the goal without intention or awareness. The goal is then pursued just as it would be if it had been instigated consciously (Bargh, 1990; Shah, 2005). In support of this argument, Chartrand and Bargh (1996) replicated two well-known information-processing goal studies, but they instigated the goals in participants without their awareness; the results were identical to those obtained when participants had been pursuing the goals consciously.

Other work has shown that participants who had achievement goals activated outside of awareness performed better on a task, and persisted on the task even when a more attractive alternative was introduced, than participants who did not have an active achievement goal (Bargh, Gollwitzer, Lee-Chai, Barndollar, \& Trötschel, 2001). Cooperation goals (Bargh et al., 2001) and affiliation goals (Lakin \& Chartrand, 2003) can also be pursued without conscious awareness or guidance. Significant others can even be a source of automatic goal activation. For example, Shah (2003) has found that performance on an experimental task increases when close significant others who would want participants to do well are made accessible to them.

\section{SUMMARY}

The research reviewed in these sections has demonstrated that people's impressions, behaviors, attitudes, and goal pursuits can be affected by automatically activated concepts. In other words, what people think, do, and feel can be influenced without conscious awareness, intention, or control. In the next section of this chapter, I turn to evidence for this contention specifically within the domain of nonverbal communication.

\section{- Automatic Nonverbal Communication}

There are several general pieces of evidence to suggest that at least some nonverbal communication is automatic. First, and as noted, there are numerous demands on relatively limited conscious cognitive resources; the sheer amount of these resources needed to process all nonverbal communication in a controlled manner makes this possibility exceedingly unlikely. Second, because the basis of verbal communication is largely conscious, humans have a tendency to direct their focus to what is said and not to focus consciously on the nonverbal cues that are, by definition, unsaid (DePaulo \& Friedman, 1998). Yet it is clear that this information is still being processed cognitively because it regulates interactions effectively (see Cappella \& Schreiber, this volume). Third, some nonverbal cues cannot be controlled easily, and when efforts to control those behaviors are exerted, they are not usually successful (see later sections in this chapter). Finally, although some researchers have argued that nonverbal communication is deliberate and strategic, there is recent evidence that even strategic behaviors can occur automatically (Lakin \& Chartrand, 2003; Lakin, Chartrand, \& Arkin, 2005); consciousness is not required for behavior to be either strategic or adaptive.

The empirical work reviewed in this chapter so far has focused on automaticity generally. I turn attention now to the subcategory of these effects that is relevant to nonverbal 
communication directly (for another review, see Choi, Gray, \& Ambady, 2005). Very little research on nonverbal communication, however, has been conducted in such a way as to show definitive evidence that the effects are occurring automatically (i.e., by reducing the likelihood of consciousness being involved, by using funneled-debriefing procedures, by having awareness checks, etc.). Nevertheless, there are several programs of research that demonstrate automatic nonverbal communication indirectly. A sensitive reader will no doubt note that the subcategories listed below correspond with some of the chapters in the Contexts and Functions sections of this Handbook. A brief, noncomprehensive review of these topics is covered here to demonstrate that some of these effects occur automatically.

\section{SOCIAL RELATIONSHIPS}

Information about social relationships is relatively easy to infer from people's nonverbal behaviors. In terms of social status, dominant people tend to stand taller, use more personal space, interrupt more, and talk louder than less dominant people (Henley, 1977; Burgoon \& Dunbar, this volume; but see Hall, 2005). Powerful people look at others the same amount when speaking as when listening, but less powerful people look more when listening than when they are speaking (Fehr \& Exline, 1987). Relationship status can also be inferred from nonverbal behaviors. Research using the Interpersonal Perception Task (IPT) (Costanzo \& Archer, 1989; see Riggio, this volume), which contains video clips of less than a minute, has demonstrated that one can accurately identify when people are related and when they are in significant relationships (Smith, Archer, \& Costanzo, 1991). Rapport can also be determined from watching people interact, at least partially because rapport is related to interactional synchrony, interpersonal distance, and eye contact (Bernieri, 1988; Bernieri, Davis, Rosenthal, \& Knee, 1994; Grahe \& Bernieri, 1999; see Tickle-Degnen, this volume). Marital status can even be determined via nonverbal means, given the surprising finding that the longer people have been married, the more similar they look (Zajonc, Adelmann, Murphy, \& Neidenthal, 1987).

Is the encoding and decoding of this social relationship information occurring automatically? As the majority of this research has not been conducted with an eye toward answering this specific question, the answer must be inferred from the methodologies that have been used, as well as some of the research findings. This information suggests several reasons to accept the argument that these processes are occurring automatically. First, decoding of social relationship information, as evidenced by research using the IPT, often occurs quickly; clips from the task are less than one minute, suggesting that people's decoding of this information must also occur very quickly (reducing the likelihood of conscious involvement). Second, certain types of conscious instructions interfere with the accuracy of decoding relationship information (e.g., Patterson \& Stockbridge, 1998; Patterson, this volume). When this type of interference happens, it suggests that people have developed automatic and efficient strategies for processing the information, and conscious attention interferes with the use of the strategies on which people typically rely.

Third, participants in studies such as the ones reviewed above can rarely identify the factors that influenced their judgments (e.g., Bernieri et al., 1994). One study even found that confederates who were instructed to create liking with a partner could not identify accurately the behaviors they used and how they used them, even though they were successful at their goal (Palmer \& Simmons, 1995). Research on 
nonconscious behavioral mimicry (reviewed in the Rapport section below) has also demonstrated that people are not consciously aware that they mimic the behaviors of others or that other people might be mimicking their behaviors or that this mimicry creates liking (Chartrand \& Bargh, 1999; Chartrand, Maddux, \& Lakin, 2005). This lack of conscious awareness is the hallmark of an automatic process.

Finally, an interesting line of research has demonstrated recently that postural complementarity, with regard to dominant and submissive nonverbal behaviors, occurs without conscious intention or control (Tiedens \& Fragale, 2003). In these studies, confederates were instructed to engage in dominant (i.e., postural expansion) or constricted (i.e., postural constriction) nonverbal behaviors, and the nonverbal behaviors of participants were measured. Results indicated that participants exhibited complementary behaviors to those of the confederate and that interactions where complementarity occurred were reported to be more comfortable. Importantly, extensive debriefing of all participants, using a funneled debriefing procedure (see Bargh \& Chartrand, 2000), revealed that they were not aware that complementarity had occurred or that it had affected the comfort level of the interaction (Tiedens $\&$ Fragale, 2003).

\section{EMOTIONAL EXPRESSION}

In addition to relationship information, people may encode information automatically about their own emotions and decode the emotions of others. In Emotional Contagion, Hatfield, Cacioppo, and Rapson (1994) synthesize a wealth of data from a variety of research subareas supporting the idea that emotions are communicated automatically and spread to other people. More often than not, this contagion occurs through nonverbal cues, such as facial expressions, tone of voice, and gestures. One particular piece of evidence that supports the idea that emotions can be encoded automatically is the fact that some emotional expressions are instantaneous and cannot be controlled (Ekman \& Davidson, 1994), two defining characteristics of automatic processes. Certain emotional facial expressions, like the Duchenne smile (Frank, Ekman, \& Friesen, 1993) or blushing (Leary, Britt, Cutlip, \& Templeton, 1992), are argued to be spontaneous depictions of enjoyment or embarrassment, respectively. The spontaneity associated with these emotional expressions could be a result of an evolutionarily developed automatic link between experiencing an emotion and nonverbal indicators of that emotion (Buck, 1984; Ekman, 1992, see Floyd, this volume), similar to the perceptionbehavior link idea reviewed earlier.

An alternative approach to understanding the spontaneity associated with emotional expressions is the behavioral ecology view (Fridlund, 1994; Fridlund \& Russell, this volume). This perspective suggests that facial displays do not reflect expressions of discrete, internal, emotional states but rather are messages that signal people's intentions within a particular context. Fridlund (1994) argues that displays of facial expressions have evolved to meet specific selection pressures and that because they reveal information about people's intentions, they are displayed to serve people's social motives. Although this approach offers a different explanation for what "emotional" facial expressions mean, this perspective also suggests that facial expressions have evolved to serve specific purposes, can occur quickly within a particular context, and often occur without conscious intention or awareness.

Some emotional facial expressions are also difficult to create consciously, suggesting that when these expressions occur, they do so automatically. For example, expressions of fear are almost impossible to 
re-create without truly being fearful (Ekman, 1985). Finally, a recent meta-analysis suggests that observers can detect accurately the state and trait anxiety of others, although the magnitude of these effects depends on the communication channel (Harrigan, Wilson, \& Rosenthal, 2004). Because anxiety is a negative emotional state that most people would not want to convey to others, this information is probably being encoded without intention or awareness.

Tone of voice may also convey information automatically about a speaker's emotional state. Neumann and Strack (2000) had participants listen to a speech that was delivered in either a slightly happy or a slightly sad voice. After hearing the text, participants rated their own mood. People's moods were affected by the tone in which the passage was read and, consistent with emotional contagion, participants automatically encoded this emotional information. When they repeated the text that they heard, they imitated the tone of the original reading spontaneously. This encoding occurred despite the fact that participants were not consciously aware of the original tone of the message and were not given instructions to mimic the original tone.

The automaticity of encoding of emotional expressions is demonstrated most clearly in research by Ulf Dimberg and colleagues (Dimberg 1982, 1997; Dimberg, Thunberg, \& Elmehed, 2000). In his work, Dimberg had participants look at pictures of people displaying happy or angry facial expressions. He then measured their subtle facial movements with electromyographic (EMG) technology. The results showed that participants moved the muscles associated with smiling when looking at the happy pictures and the muscles associated with frowning when looking at the angry pictures. This effect occurred even when the facial expressions were presented outside of conscious awareness (i.e., subliminally), suggesting that this decoding can occur automatically.

\section{PREJUDICE}

Prejudice, or negative feelings about groups of people, can also be communicated automatically through nonverbal cues (see Dovidio, Hebl, Richeson, \& Shelton, this volume). Because categorical information (e.g., race, sex; Brewer, 1988; Fiske \& Neuberg, 1990) is processed automatically in most cases, simply seeing a member of a stereotyped group can activate, without awareness, thoughts and feelings about that group (Blair, 2002; Devine, 1989; Fiske, 1998). It has been argued that a dissociation often exists between people's conscious and unconscious attitudes toward minority groups; therefore, researchers have been able to measure both and determine the effects that each has on social interactions.

This work has shown that nonverbal behaviors like gaze, blinking, body posture, and interpersonal distance can indicate prejudiced feelings toward interaction partners (Crosby, Bromley, \& Saxe, 1980; McConnell \& Liebold, 2001; Towles-Schwen \& Fazio, 2003). In one demonstration, people who indicated negative feelings toward Blacks on an implicit measure of prejudice also blinked more (a sign of uncomfortableness) and made less eye contact during an interaction with an African American partner (Dovidio, Kawakami, Johnson, Johnson, \& Howard, 1997). Dovidio, Kawakami, and Gaertner (2002) replicated this effect and showed that the less positive nonverbal behaviors of participants who had implicit racial biases led the African American partners of these participants to feel that the interaction had been less friendly.

Likewise, Vanman, Saltz, Nathan, and Warren (2004) have also shown that facial EMG activity can be related to another 
person's race; participants who had cheek EMG activity (i.e., activity that would be associated with smiling) when viewing pictures of White targets were more likely to nominate a White applicant for a prestigious award than a Black applicant. Participants in these studies were not aware of the negative nonverbal behaviors they encoded or the fact that these nonverbal behaviors were affecting their interactions negatively. This work therefore provides evidence that both encoding and decoding of prejudicial feelings can occur automatically. In fact, as Dovidio et al. (2002) have discussed, researchers first turned to nonverbal behaviors as indicators of prejudice because of their hypothesized "leakiness" (i.e., uncontrollability) and spontaneity.

\section{IMPRESSION MANAGEMENT AND PERSONALITY EXPRESSION}

Although impression management and self-presentation can certainly be conscious (see Keating, this volume), these communicative functions can also occur relatively effortlessly and without conscious guidance, particularly in cases where people are not particularly motivated to convey a desired identity. Moreover, it is also clear that people may infer traits and make attributions from the nonverbal behaviors of others automatically and that these judgments can be quite accurate. Together, this literature suggests that people often express their personality and decode personality information about others automatically through nonverbal behaviors.

People tend to use different self-presentational strategies in different situations and with different types of people. For example, when people are instructed to make an interaction partner like them, they nod, smile, and make more eye contact than do people who did not receive these instructions (Godfrey, Jones, \& Lord, 1986). People copy the postures of interaction partners more when they are told those partners might be helpful than when opportunities to get help from the partners are not available (La France, 1985). Nonverbal behaviors are also dependent on the people for whom the display occurs (see DePaulo \& Friedman, 1998, for a review). Finally, the ecological theory of perception suggests that people are able to gain, relatively automatically, information about other people from their appearances and movements, information that Gibson (1979) calls affordances. This information is able to be gathered easily because appearance and behavior express some personality characteristics accurately (Zebrowitz \& Collins, 1997).

Nonverbal communication is therefore sensitive to conscious goals and situational constraints. Although this strategic use of nonverbal behaviors suggests that their cognitive basis is conscious, being strategic does not demand consciousness. There are several lines of research that suggest that people alter their nonverbal behaviors automatically. Tice, Butler, Muraven, and Stillwell (1995) hypothesized that people's default self-presentational strategy with strangers is to present a positive image, whereas people's default self-presentational strategy with friends is to present a modest image. Consistent with this proposition, when participants behaved consistently with their default tendencies, their self-presentations used few cognitive resources, which led to increased memory of the details of the interaction. Participants who used nondefault self-presentational strategies (e.g., modesty with strangers) were not able to pursue these strategies automatically and used conscious cognitive resources to accomplish their goals (see also Patterson, Churchill, Farag, \& Borden, 1991/1992). Other research has also demonstrated that self-presenting in a way that is inconsistent with personality is 
cognitively taxing and requires attentional resources (Pontari \& Schlenker, 2000).

Attributional processes, whereby people infer traits and make dispositional or situational attributions, can also happen automatically. An extensive literature on spontaneous trait inferences has demonstrated that simply presenting people with descriptions of other people's behaviors results in inferring traits from them (Uleman, 1999; Uleman et al., 1996). Participants in these studies were not instructed to infer traits and typically even denied that they had done so (Winter \& Uleman, 1984). Related research has found that people might also make emotion inferences when reading descriptions of other's behavior automatically (Gernsbacher, Goldsmith, \& Robertson, 1992). Finally, people make both dispositional and situational attributions without the use of limited cognitive resources or conscious intention (Gilbert, Pelham, \& Krull, 1988; Krull, 1993). Thus, when people perceive the behaviors of others, they seem to decode this information effortlessly and unintentionally, at least in most circumstances.

Automatic self-presentation, impression management, trait inferences, and attributions are likely to be beneficial to most people in most situations but only to the extent that these relatively effortless categorizations are correct. Ambady and her colleagues have demonstrated that people's automatic decodings of the behaviors of others are remarkably accurate (Ambady, Bernieri, \& Richeson, 2000; Gray \& Ambady, this volume). In one empirical demonstration, participants watched video clips of teachers' nonverbal behaviors, some as short as six seconds, and then judged teacher effectiveness. Participants' ratings were strongly correlated with students' end-of-semester ratings (Ambady \& Rosenthal, 1993).

A meta-analysis has revealed a medium to large effect size for accuracy of predictions from nonverbal presentations and that length of observation time did not significantly affect accuracy; accuracy was just as good when people observed behavior for 30 seconds as it was when people observed behavior for five minutes (Ambady \& Rosenthal, 1992). The fact that people can be so accurate at decoding in such short time frames suggests that the process is likely not occurring with much conscious intention or guidance. Moreover, when conscious attention is devoted to this type of task, decoding accuracy decreases (Gilbert \& Krull, 1988; Patterson \& Stockbridge, 1998).

\section{EXPECTANCIES}

Just as people convey personality through their nonverbal behaviors, expectancies that a person holds for others are also conveyed through nonverbal behaviors, seemingly without intention or awareness (see Remland, this volume). Communication of these expectancies-in certain contexts and under certain conditions-results in a self-fulfilling prophecy, whereby perceivers elicit behaviors that are consistent with their original ideas and then conclude that their expectancies were truthful, without realizing the role that they have played in confirming them (Rosenthal, 2003). For example, researchers' behaviors can affect the responses of their participants (Rosenthal, 1976), and the expectations of teachers have been found to affect the behaviors of their students (Rosenthal \& Jacobson, 1968). That people are unaware that they have elicited the behavior they expected suggests that these expectancies are being conveyed automatically. This is particularly the case when negative expectancies are conveyed, which would likely be controlled if people were aware of them (e.g., Word, Zanna, \& Cooper, 1974).

There is also evidence that people are affected automatically by the expectancies 
that others have for them (i.e., automatic decoding of expectancies). Word et al. (1974) showed that when White participants in a second study were treated as Black participants had been treated in a first study (e.g., abrupt questioning, lack of eye contact), the quality of the interaction decreased. The White participants stuttered more and made less eye contact as a result of the expectancies for a less successful interview that the interviewer was conveying. Chen and Bargh (1997) found a similar result: When stereotypes of African Americans were activated outside of conscious awareness, participants treated an interaction partner in a way that was consistent with this stereotype, eliciting more hostility. Participants were unaware that the stereotype had been activated and were unaware that their own behavior was influencing the behavior of their interaction partner. The results of this study are consistent with many other research findings that stereotype activation results in stereotype-consistent behaviors (see Wheeler \& Petty, 2001, for a review). Again, these studies demonstrate consistently that people are not aware that their behavior is affected or is being affected by the expectancies of others.

\section{RAPPORT}

Not all behaviors that occur outside of awareness are problematic. For example, many people have been interested in the relationship between posture sharing (either mimicking or mirroring) and the development and maintenance of rapport (for a review, see Tickle-Degnen, this volume). The fact that people mimic the nonverbal behaviors of others (both significant others and strangers) has long been established (Chartrand et al., 2005). Further work has demonstrated that people tend to mimic others and thereby demonstrate or develop rapport without intention, control, or conscious awareness (e.g., Bavelas, Black, Lemery, \& Mullett, 1986; Bernieri, 1988; Bernieri, Reznick, \& Rosenthal, 1988; La France, 1979, 1982; La France \& Broadbent, 1976). Because this research does not typically include awareness checks or attempts to rule out conscious involvement, the automaticity of these effects is, again, inferred from participants' apparent lack of awareness.

There is more definitive evidence that behavioral mimicry can occur nonconsciously, however, and that this automatic mimicry results in smoother interactions and the development of liking. Chartrand and Bargh (1999) found that participants mimicked the nonverbal behaviors of a confederate without conscious awareness. In a second study, they found that mimicry leads to increased liking for the mimicker and smoother interactions. Thus, mimicking others and being mimicked can communicate rapport automatically. This finding is consistent with the work of Lakin and Chartrand (2003), who found that participants who pursue an unconscious affiliation goal are more likely to mimic the behaviors of an interaction partner than participants who do not have an active affiliation goal (see also Lakin, Jefferis, Cheng, \& Chartrand, 2003).

A second study expanded on this finding by giving participants who had a nonconsciously activated affiliation goal a success or failure experience (Lakin \& Chartrand, 2003). Participants either succeeded (i.e., had a pleasant interaction with a confederate) or failed at their goal (i.e., had a relatively less pleasant interaction with a confederate). In a subsequent interaction with a different confederate, participants who still had affiliation goals (i.e., those who initially failed) mimicked the nonverbal behaviors of their interaction partner more than participants who had been successful. This effect occurred despite the fact that participants did not consciously know they were 
pursuing an affiliation goal and did not consciously acknowledge the confederate's behaviors or how the confederate's behaviors were affecting their own behaviors.

A recent social exclusion experience may also lead to increases in behavioral mimicry (Lakin et al., 2005; Lakin \& Chartrand, 2005). The need to belong is one of the strongest core motivations, and it affects people's thoughts, feelings, and behaviors frequently (Williams, Forgas, \& von Hippel, 2005). It is therefore not surprising that when people have been excluded from a social group, they will engage in behaviors that help them to create liking and allow them to reenter the group. Recent research has shown that mimicking the nonverbal behaviors of group members may be one such strategy (Lakin et al., 2005). When participants were excluded from a computerized ball-tossing game and then interacted with a confederate in a different context, they mimicked the behaviors of the confederate more than when they had not been excluded during the ball-toss game. In other words, participants who were trying to create liking and affiliation were able to pursue this goal through mimicking another person. Together with the findings from Lakin and Chartrand (2003), this work suggests that people can pursue a goal to develop rapport or liking by mimicking the behaviors of others automatically.

Finally, paradigms that involve having a confederate mimic the behaviors of participants have demonstrated that being mimicked causes people to be more interdependent (van Baaren, Maddux, Chartrand, de Bouter, \& van Knippenberg, 2003), be more helpful (van Baaren, Holland, Kawakami, \& van Knippenberg, 2004), and provide bigger tips (van Baaren, Holland, Steenaert, \& van Knippenberg, 2003; for an overview, see Tickle-Degnen, this volume). Mimicry also leads to greater persuasion (Bailenson \& Yee, 2005). Because work on mimicry typically compares participants who are mimicked with participants who are not mimicked, these effects occur arguably as a direct result of the positive feelings that occur automatically with mimicry. The majority of this work includes awareness checks and other methodological strategies that reduce the role of consciousness in these effects (Bargh \& Chartrand, 2000).

\section{- Discussion and Future Directions}

As the literatures reviewed above demonstrate, nonverbal behaviors can communicate information automatically about social relationships, emotions, prejudice, personality, and expectations, as well as indicate relationship status and rapport. As a whole, this research compellingly argues that nonverbal communication has, at least in part, its basis in automatic processes. There are, however, several important topics that deserve research attention.

\section{METHODOLOGICAL CONCERNS}

Whereas not all the research reviewed here has provided definitive evidence that the processes are occurring without awareness, intention, control, or cognitive effort, the several lines of research that do provide this evidence demonstrate that nonverbal communication can and does occur automatically. Moreover, the research that does not contain definitive evidence often has methodological characteristics suggesting that people are not aware of what their nonverbal behaviors are communicating or the extent to which their own thoughts, feelings, and behaviors are being affected by the nonverbal communications of others.

Although this suggests that a significant component of nonverbal communication 
is occurring automatically, to determine definitively the role that automatic processes play in nonverbal communication, researchers should consider including methodological strategies in future research that would reduce the role of controlled processes. For example, participants could be encouraged to make judgments and decisions quickly to reduce their reliance on conscious processes, or they could be put under cognitive load so that their available cognitive resources would be split among several tasks. Researchers could also include awareness checks or funneled debriefings to determine how aware people are of their cognitive processes (Bargh \& Chartrand, 2000). By using these sorts of methodologies, future research will be better able to determine the relative contribution of automatic processes to nonverbal communication.

\section{ROLE OF CONTROLLED PROCESSES}

Even though I have argued that much of nonverbal communication appears to occur automatically, it would be a mistake to assume that there is no controlled cognitive basis to nonverbal communication as well. We may be unaware of the nonverbal cues that we encode typically, but we can direct our "internal eye" easily onto these behaviors and therefore become more aware of them. People may not process the nonverbal messages they receive from others consciously, but if something causes a disruption in their automatic processing (e.g., an unusual event), or if people are motivated to learn about another person, that process can easily become conscious. Finally, people may even try to control (i.e., with intention and awareness, and with varying degrees of success) their nonverbal behaviors (although even control can become automatized with enough practice; see Kawakami, Dovidio, Moll, Hermsen, \& Russin, 2000).
Future work in nonverbal communication would benefit from explicit acknowledgment of the role that both automatic and controlled processes play in the encoding and decoding of nonverbal behaviors. For example, Patterson (2001, this volume) has taken this approach in his parallel process model. He integrated encoding and decoding of nonverbal communication into a single framework by suggesting that these processes occur in parallel and that they both can be more or less controlled cognitive processes. In addition, he argued that factors like biology, culture, personality, situational constraints, interpersonal expectancies, affect, and goals can affect people's social cognition. The parallel process model therefore synthesizes much of the work that social psychologists, communication scholars, and others were conducting on nonverbal communication already (see Patterson, 2001, for a review), which is an important first step in creating a more complete understanding of nonverbal communication processes.

This model also has several interesting implications for the study of the cognitive processes related to nonverbal communication. First, the parallel process model implies that people are sophisticated users and consumers of nonverbal cues. The fact that encoding and decoding occur in parallel demonstrates that neither process requires extensive cognitive resources (i.e., that neither process is particularly effortful). This implication is consistent with my argument that much of nonverbal communication occurs automatically, perhaps even that which appears to be used relatively strategically. Arguably, we have evolved automatic strategies to deal with the incredible amounts of social information that we must process and to help us accomplish our important objectives and goals. Given the importance of nonverbal cues, it is not surprising that automatic nonverbal 
communication would also be evolutionarily adaptive.

\section{IMPORTANCE OF COGNITIVE RESOURCES}

Another interesting area for future research to explore is the role of cognitive resources in nonverbal communication. Because cognitive resources are limited, the amount of cognitive resources that a person has will be a crucial factor determining whether a person is able to use controlled processes to decode nonverbal communication. For example, the parallel process model would predict that when cognitive resources are devoted to encoding or decoding for whatever reason (i.e., we are particularly motivated to convey an impression, we are interested in an interaction partner's intentions), they will be less available to the other process (because they occur in parallel). In other words, if we have to think about encoding, fewer resources can be devoted to decoding. This could have important implications for situations where people need to be focused specifically on one process or the other. Alternatively, because both the sending and the receiving of nonverbal cues can be relatively automatic, one could argue that devoting resources to one process would not necessarily cause the other to deteriorate (because it would be relatively automatic). Future research on nonverbal communication will need to explore these different possibilities; determining how cognitive resources affect nonverbal communication will provide important insight into how automatic these processes really are.

\section{$\checkmark$ Conclusion}

Nonverbal communication conveys information automatically about our social relationships, emotions, prejudices, personalities, and expectations, as well as indicates existing levels of rapport or the desire to create rapport. The cognitive processes that underlie this important source of information, however, are not always automatic. Parallel process models, or other models that recognize explicitly the role for both automatic and controlled processes in nonverbal communication, will likely represent the future of research in this area. Ironically, with more awareness of automatic processes, we should have a greater appreciation of the importance of nonverbal communication.

\section{- References}

Ambady, N., Bernieri, F. J., \& Richeson, J. A. (2000). Toward a histology of social behavior: Judgmental accuracy from thin slices of the behavioral stream. In M. P. Zanna (Ed.), Advances in experimental social psychology (Vol. 32, pp. 201-271). San Diego, CA: Academic Press.

Ambady, N., \& Rosenthal, R. (1992). Thin slices of expressive behavior as predictors of interpersonal consequences: A meta-analysis. Psychological Bulletin, 111, 256-274.

Ambady, N., \& Rosenthal, R. (1993). Half a minute: Predicting teacher evaluations from thin slices of nonverbal behavior and physical attractiveness. Journal of Personality and Social Psychology, 64, 431-441.

Bailenson, J. N., \& Yee, N. (2005). Digital chameleons: Automatic assimilation of nonverbal gestures in immersive virtual environments. Psychological Science, 16, 814-819.

Bargh, J. A. (1990). Auto-motives: Preconscious determinants of social interaction. In E. T. Higgins \& R. Sorrentino (Eds.), Handbook of motivation and cognition (Vol. 2, pp. 93-130). New York: Guilford Press.

Bargh, J. A. (1994). The four horsemen of automaticity: Awareness, intention, efficiency, and control in social cognition. In R. S. Wyer \& T. K. Srull (Eds.), Handbook of 
social cognition (2nd ed., pp. 1-40). Hillsdale, NJ: Erlbaum.

Bargh, J. A. (1996). Automaticity in social psychology. In E. T. Higgins \& A. W. Kruglanski (Eds.), Social psychology: Handbook of basic principles (pp. 169183). New York: Guilford Press.

Bargh, J. A. (1997). The automaticity of everyday life. In R. S. Wyer (Ed.), The automaticity of everyday life: Advances in social cognition (Vol. 10, pp. 1-61). Mahwah, NJ: Erlbaum.

Bargh, J. A., Chaiken, S., Govender, R., \& Pratto, F. (1992). The generality of the automatic attitude activation effect. Journal of Personality and Social Psychology, 62, 893-912.

Bargh, J. A., \& Chartrand, T. L. (1999). The unbearable automaticity of being. American Psychologist, 54, 462-479.

Bargh, J. A., \& Chartrand, T. L. (2000). The mind in the middle: A practical guide to priming and automaticity research. In H. T. Reis \& C. M. Judd (Eds.), Handbook of research methods in social and personality psychology (pp. 253-285). New York: Cambridge University Press.

Bargh, J. A., Chen, M., \& Burrows, L. (1996). Automaticity of social behavior: Direct effects of trait construct and stereotype activation on action. Journal of Personality and Social Psychology, 71, 230-244.

Bargh, J. A., Gollwitzer, P. M., Lee-Chai, A., Barndollar, K., \& Trötschel, R. (2001). The automated will: Nonconscious activation and pursuit of behavioral goals. Journal of Personality and Social Psychology, 81, 1014-1027.

Bavelas, J. B., Black, A., Lemery, C. R., \& Mullett, J. (1986). "I show how you feel": Motor mimicry as a communicative act. Journal of Personality and Social Psychology, 50, 322-329.

Bernieri, F. J. (1988). Coordinated movement and rapport in teacher-student interactions. Journal of Nonverbal Behavior, 12, 120-138.

Bernieri, F. J., Davis, J. M., Rosenthal, R., \& Knee, C. R. (1994). Interactional synchrony and rapport: Measuring synchrony in displays devoid of sound and facial affect.
Personality and Social Psychology Bulletin, 20, 303-311.

Bernieri, F. J., Reznick, J. S., \& Rosenthal, R. (1988). Synchrony, pseudosynchrony, and dissynchrony: Measuring the entertainment process in mother-infant interactions. Journal of Personality and Social Psychology, 54, 243-253.

Blair, I. V. (2002). The malleability of automatic stereotypes and prejudice. Personality and Social Psychology Review, 6, 242-261.

Brewer, M. B. (1988). A dual process model of impression formation. In T. K. Srull \& R. S. Wyer (Eds.), Advances in social cognition (Vol. 1, pp. 1-36). Hillsdale, NJ: Erlbaum Associates.

Buck, R. (1984). The communication of emotion. New York: Guilford.

Carver, C. S., Ganellen, R. J., Froming, W. J., \& Chambers, W. (1983). Modeling: An analysis in terms of category accessibility. Journal of Experimental Social Psychology, 19, 403-421.

Chartrand, T. L., \& Bargh, J. A. (1996). Automatic activation of impression formation and memorization goals: Nonconscious goal priming reproduces effects of explicit task instructions. Journal of Personality and Social Psychology, 71, 464-478.

Chartrand, T. L., \& Bargh, J. A. (1999). The chameleon effect: The perception-behavior link and social interaction. Journal of Personality and Social Psychology, 76, 893-910.

Chartrand, T. L., Maddux, W. W., \& Lakin, J. L. (2005). Beyond the perception-behavior link: The ubiquitous utility and motivational moderators of nonconscious mimicry. In R. R. Hassin, J. S. Uleman, \& J. A. Bargh (Eds.), The new unconscious (pp. 334-361). New York: Oxford University Press.

Chen, M., \& Bargh, J. A. (1997). Nonconscious behavioral confirmation processes: The selffulfilling nature of automatically-activated stereotypes. Journal of Experimental Social Psychology, 33, 541-560.

Choi, Y. S., Gray, H. M., \& Ambady, N. (2005). The glimpsed world: Unintended communication and unintended perception. In 
R. R. Hassin, J. S. Uleman, \& J. A. Bargh (Eds.), The new unconscious (pp. 309-333). New York: Oxford University Press.

Costanzo, M., \& Archer, D. (1989). Interpreting the expressive behavior of others: The Interpersonal Perception Task. Journal of Nonverbal Behavior, 13, 225-245.

Crosby, F., Bromley, S., \& Saxe, L. (1980). Recent unobtrusive studies of Black and White discrimination and prejudice: A literature review. Psychological Bulletin, 87, 546-563.

DePaulo, B. M., \& Friedman, H. S. (1998). Nonverbal communication. In D. T. Gilbert, S. T. Fiske, \& G. Lindzey (Eds.), The handbook of social psychology (4th ed., pp. 3-40). New York: Oxford University Press.

Devine, P. G. (1989). Stereotypes and prejudice: Their automatic and controlled components. Journal of Personality and Social Psychology, 56, 5-18.

Dijksterhuis, A., Aarts, H., Bargh, J. A., \& van Knippenberg, A. (2000). On the relation between associative strength and automatic behavior. Journal of Experimental Social Psychology, 36, 531-544.

Dijksterhuis, A., \& Bargh, J. A. (2001). The perception-behavior expressway: Automatic effects of social perception on social behavior. In M. P. Zanna (Ed.), Advances in Experimental Social Psychology (Vol. 33, pp. 1-40). San Diego, CA: Academic Press.

Dijksterhuis, A., \& van Knippenberg, A. (1998). The relation between perception and behavior or how to win a game of Trivial Pursuit. Journal of Personality and Social Psychology, 74, 865-877.

Dijksterhuis, A., \& van Knippenberg, A. (2000). Behavioral indecision: Effects of self-focus on automatic behavior. Social Cognition, 18, 55-74.

Dijksterhuis, A., Spears, R., \& Lepinasse, V. (2001). Reflecting and deflecting stereotypes: Assimilation and contrast in impression formation and automatic behavior. Journal of Experimental Social Psychology, 37, 286-299.

Dimberg, U. (1982). Facial reactions to facial expressions. Psychophysiology, 19, 643-647.
Dimberg, U. (1997). Psychophysiological reactions to facial expressions. In U. Segerstrale \& P. Molnar (Eds.), Nonverbal communication: Where nature meets culture (pp. 47-60). Mahwah, NJ: Erlbaum.

Dimberg, U., Thunberg, M., \& Elmehed, K. (2000). Unconscious facial reactions to emotional facial expressions. Psychological Science, 11, 86-89.

Dovidio, J. F., Kawakami, K., \& Gaertner, S. L. (2002). Implicit and explicit prejudice and interracial interaction. Journal of Personality and Social Psychology, 82, 62-68.

Dovidio, J. F., Kawakami, K., Johnson, C., Johnson, B., \& Howard, A. (1997). On the nature of prejudice: Automatic and controlled processes. Journal of Experimental Social Psychology, 33, 510-540.

Ekman, P. (1985). Telling lies. New York: Norton.

Ekman, P. (1992). An argument for basic emotions. Cognition and Emotion, 6, 169-200.

Ekman, P., \& Davidson, R. J. (Eds.). (1994). The nature of emotion. New York: Oxford University Press.

Epley, N., \& Gilovich, T. (1999). Just going along: Nonconscious priming and conformity to social pressure. Journal of Personality and Social Psychology, 35, 578-589.

Fazio, R. H., Sanbonmatsu, D. M., Powell, M. C., \& Kardes, F. R. (1986). On the automatic activation of attitudes. Journal of Personality and Social Psychology, 50, 229-238.

Fehr, B. J., \& Exline, R. V. (1987). Social visual interaction: A conceptual and literature review. In S. Feldstein \& A. W. Siegman (Eds.), Nonverbal behavior and communication (2nd ed., pp. 225-325). Hillsdale, NJ: Erlbaum.

Fiske, S. T. (1998). Stereotyping, prejudice, and discrimination. In D. T. Gilbert, S. T. Fiske, \& G. Lindzey (Eds.), The handbook of social psychology (4th ed., pp. 357-411). New York: Oxford University Press.

Fiske, S. T., \& Neuberg, S. L. (1990). A continuum of impression formation, from category-based to individuating processes: Influences of information and motivation 
on attention and interpretation. In M. P. Zanna (Ed.), Advances in Experimental Social Psychology (Vol. 23, pp. 1-74). San Diego, CA: Academic Press.

Frank, M. G., Ekman, P., \& Friesen, W. V. (1993). Behavioral markers and recognizability of the smile of enjoyment. Journal of Personality and Social Psychology, 64, 83-93.

Fridlund, A. J. (1994). Human facial expression. San Diego, CA: Academic Press.

Gernsbacher, M. A., Goldsmith, H. H., \& Robertson, R. R. (1992). Do readers mentally represent characters' emotional states? Cognition and Emotion, 6, 89-111.

Gibson, J. J. (1979). The ecological approach to visual perception. Boston: Houghton Mifflin.

Gilbert, D. T., \& Krull, D. S. (1988). Seeing less and knowing more: The benefits of perceptual ignorance. Journal of Personality and Social Psychology, 54, 193-202.

Gilbert, D. T., Pelham, B. W., \& Krull, D. S. (1988). On cognitive busyness: When person perceivers meet persons perceived. Journal of Personality and Social Psychology, 54, 733-740.

Godfrey, D. K., Jones, E. E., \& Lord, C. G. (1986). Self-promotion is not ingratiating. Journal of Personality and Social Psychology, 50, 106-115.

Grahe, J. E., \& Bernieri, F. J. (1999). The importance of nonverbal cues in judging rapport. Journal of Nonverbal Behavior, 23, 253-269.

Hall, J. A. (2005). Meta-analysis of nonverbal behavior. In V. Manusov (Ed.), The sourcebook of nonverbal measures: Going beyond words (pp. 483-492). Mahwah, NJ: Erlbaum Associates.

Harrigan, J. A., Wilson, K., \& Rosenthal, R. (2004). Detecting state and trait anxiety from auditory and visual cues: A metaanalysis. Personality and Social Psychology Bulletin, 30, 56-66.

Hassin, R. R., Uleman, J. S., \& Bargh, J. A. (Eds.). (2005). The new unconscious. New York: Oxford University Press.

Hatfield, E., Cacioppo, J. T., \& Rapson, R. L. (1994). Emotional contagion. Cambridge: Cambridge University Press.
Henley, N. M. (1977). Body politics: Power, sex and nonverbal communication. Englewood Cliffs, NJ: Prentice Hall.

Higgins, E. T. (1996). Knowledge activation: Accessibility, applicability, and salience. In E. T. Higgins \& A. W. Kruglanski (Eds.), Social psychology: Handbook of basic principles (pp. 133-168). New York: Guilford Press.

Higgins, E. T., Rholes, W. S., \& Jones, C. R. (1977). Category accessibility and impression formation. Journal of Experimental Social Psychology, 13, 141-154.

Krull, D. S. (1993). Does the grist change the mill? The effect of the perceiver's inferential goal on the process of social inference. Personality and Social Psychology Bulletin, 19, 340-348.

Kawakami, K., Dovidio, J. F., \& Dijksterhuis, A. (2003). Effect of social category priming on personal attitudes. Psychological Science, 14, 315-319.

Kawakami, K., Dovidio, J. F., Moll, J., Hermsen, S., \& Russin, A. (2000). Just say no (to stereotyping): Effects of training in the negation of stereotypic associations on stereotype activation. Journal of Personality and Social Psychology, 78, 871-888.

La France, M. (1979). Nonverbal synchrony and rapport: Analysis by the cross-lag panel technique. Social Psychology Quarterly, 42, 66-70.

La France, M. (1982). Posture mirroring and rapport. In M. Davis (Ed.), Interaction rhythms: Periodicity in communicative behavior (pp. 279-298). New York: Human Sciences Press.

La France, M. (1985). Postural mirroring and intergroup relations. Personality and Social Psychology Bulletin, 11, 207-217.

La France, M., \& Broadbent, M. (1976). Group rapport: Posture sharing as a nonverbal indicator. Group and Organization Studies, 1, 328-333.

Lakin, J. L., \& Chartrand, T. L. (2003). Using nonconscious behavioral mimicry to create affiliation and rapport. Psychological Science, 14, 334-339.

Lakin, J. L., \& Chartrand, T. L. (2005). Exclusion and nonconscious behavioral mimicry. In 
K. D. Williams, J. P. Forgas, \& W. von Hippel (Eds.), The social outcast: Ostracism, social exclusion, rejection, and bullying (pp. 279-295). New York: Psychology Press.

Lakin, J. L., Chartrand, T. L., \& Arkin, R. M. (2005). I am too just like you: Nonconscious mimicry as a behavioral response to social exclusion. Unpublished manuscript.

Lakin, J. L., Jefferis, V. E., Cheng, C. M., \& Chartrand, T. L. (2003). The chameleon effect as social glue: Evidence for the evolutionary significance of nonconscious mimicry. Journal of Nonverbal Behavior, 27, 145-162.

Leary, M. R., Britt, T. W., Cutlip, W. D., II., \& Templeton, J. L. (1992). Social blushing. Psychological Bulletin, 112, 446-460.

Levy, B. (1996). Improving memory in old age through implicit self-stereotyping. Journal of Personality and Social Psychology, 71, 1092-1107.

Macrae, C. N., \& Johnston, L. (1998). Help, I need somebody: Automatic action and inaction. Social Cognition, 16, 400-417.

McConnell, A. R., \& Liebold, J. M. (2001). Relations among the Implicit Association Test, discriminatory behavior, and explicit measures of racial attitudes. Journal of Experimental Social Psychology, 37, $435-442$.

Neisser, U. (1967). Cognitive psychology. Englewood Cliffs, NJ: Prentice Hall.

Neumann, R., \& Strack, F. (2000). "Mood contagion": The automatic transfer of mood between persons. Journal of Personality and Social Psychology, 79, 211-223.

Palmer, M. T., \& Simmons, K. B. (1995). Communicating intentions through nonverbal behaviors: Conscious and nonconscious encoding of liking. Human Communication Research, 22, 128-160.

Patterson, M. L. (2001). Toward a comprehensive model of nonverbal communication. In W. P. Robinson \& H. Giles (Eds.), The new handbook of language and social psychology (pp. 159-176). New York: Wiley.

Patterson, M. L., Churchill, M. E., Farag, F., \& Borden, E. (1991/1992). Impression management, cognitive demand, and interpersonal sensitivity. Current Psychology: Research \& Reviews, 10, 263-271.
Patterson, M. L., \& Stockbridge, E. (1998). Effects of cognitive demand and judgment strategy on person perception accuracy. Journal of Nonverbal Behavior, 22, 253-263.

Pontari, B. A., \& Schlenker, B. R. (2000). The influence of cognitive load on self-presentation: Can cognitive busyness help as well as harm social performance? Journal of Personality and Social Psychology, 78, 1092-1108.

Posner, M. I., \& Snyder, C. R. R. (1975). Attention and cognitive control. In R. L. Solso (Ed.), Information processing and cognition: The Loyola symposium (pp. 55-85). Hillsdale, NJ: Erlbaum.

Rosenthal, R. (1976). Experimenter effects in behavioral research. New York: Irvington.

Rosenthal, R. (2003). Covert communication in laboratories, classrooms, and the truly real world. Current Directions in Psychological Science, 12, 151-154.

Rosenthal, R., \& Jacobson, L. (1968). Pygmalion in the classroom. New York: Holt, Rinehart, \& Winston.

Shah, J. Y. (2003). Automatic for the people: How representations of significant others implicitly affect goal pursuit. Journal of Personality and Social Psychology, 84, 661-681.

Shah, J. Y. (2005). The automatic pursuit and management of goals. Current Directions in Psychological Science, 14, 10-13.

Shiffrin, R. M., \& Schneider, W. (1977). Controlled and automatic human information processing: II. Perceptual learning, automatic attending and a general theory. Psychological Review, 84, 127-190.

Smith, H. J., Archer, D., \& Costanzo, M. (1991). "Just a hunch": Accuracy and awareness in person perception. Journal of Nonverbal Behavior, 15, 3-18.

Srull, T. K., \& Wyer, R. S. (1979). The role of category accessibility in the interpretation of information about persons: Some determinants and implications. Journal of Personality and Social Psychology, 37, 1660-1672.

Steele, C. M., \& Aronson, J. (1995). Stereotype threat and the intellectual test performance of African Americans. Journal of 
Personality and Social Psychology, 69, 797-811.

Tice, D. M., Butler, J. L., Muraven, M. B., \& Stillwell, A. M. (1995). When modesty prevails: Differential favorability of selfpresentation to friends and strangers. Journal of Personality and Social Psychology, 69, 1120-1138.

Tiedens, L. Z., \& Fragale, A. R. (2003). Power moves: Complementarity in dominant and submissive nonverbal behavior. Journal of Personality and Social Psychology, 84, 558-568.

Towles-Schwen, T., \& Fazio, R. H. (2003). Choosing social situations: The relation between automatically activated racial attitudes and anticipated comfort interacting with African Americans. Personality and Social Psychology Bulletin, 29, 170-182.

Uleman, J. S. (1999). Spontaneous versus intentional inferences in impression formation. In S. Chaiken \& Y. Trope (Eds.), Dual-process theories in social psychology (pp. 141-160). New York: Guilford Press.

Uleman, J. S., Newman, L. S., \& Moskowitz, G. B. (1996). People as flexible interpreters: Evidence and issues from spontaneous trait inference. In M. P. Zanna (Ed.), Advances in Experimental Social Psychology (Vol. 28, pp. 179-211). San Diego, CA: Academic Press. van Baaren, R. B., Holland, R. W., Kawakami, K., \& van Knippenberg, A. (2004). Mimicry and prosocial behavior. Psychological Science, 15, 71-74.

van Baaren, R. B., Holland, R. W., Steenaert, B., \& van Knippenberg, A. (2003). Mimicry for money: Behavioral consequences of imitation. Journal of Experimental Social Psychology, 39, 393-398.

van Baaren, R. B., Maddux, W. W., Chartrand, T. L., de Bouter, C., \& van Knippenberg, A. (2003). It takes two to mimic: Behavioral consequences of self-construals. Journal of Personality and Social Psychology, 84, 1093-1102.

Vanman, E. J., Saltz, J. L., Nathan, L. R., \& Warren, J. A. (2004). Racial discrimination by low-prejudiced Whites facial movements as implicit measures of attitudes related to behavior. Psychological Science, 15, 711-714.

Wheeler, S. C., Jarvis, W. B. G., \& Petty, R. E. (2000). Think unto others: The self-destructive impact of negative racial stereotypes. Journal of Experimental Social Psychology, 37, 173-180.

Wheeler, S. C., \& Petty, R. E. (2001). The effects of stereotype activation on behavior: A review of possible mechanisms. Psychological Bulletin, 127, 797-826.

Williams, K. D., Forgas, J. P., \& von Hippel, W. (Eds.). (2005). The social outcast: Ostracism, social exclusion, rejection, and bullying. New York: Psychology Press.

Winter, L., \& Uleman, J. S. (1984). When are social judgments made? Evidence for the spontaneousness of trait inferences. Journal of Personality and Social Psychology, 47, 237-252.

Word, C. O., Zanna, M. P., \& Cooper, J. (1974). The nonverbal mediation of selffulfilling prophecies in interracial interaction. Journal of Experimental Social Psychology, 10, 109-120.

Zajonc, R. B. (1980). Feeling and thinking: Preferences need no inferences. American Psychologist, 35, 151-175.

Zajonc, R. B., Adelmann, P. K., Murphy, S. T., \& Neidenthal, P. M. (1987). Convergence in the physical appearance of spouses. Motivation and Emotion, 11, 335-346.

Zebrowitz, L. A., \& Collins, M. A. (1997). Accurate social perception at zero acquaintance: The affordances of a Gibsonian approach. Personality and Social Psychology Review, 1, 204-223. 
04-Manusov.qxd 6/30/2006 7:23 PM Page 78 